\title{
25 \\ Using Technology for Tutor and Student Learning Exchange
}

\author{
Katherine Hewlett \\ Norwich University College of the Arts
}

This project built upon the AchieveAbility initiative, which develops materials and training for teaching specific learning difference learners in schools and colleges. AchieveAbility devised the concept for the 'InCurriculum' Project and brought together a consortium of United Kingdom higher education institutions to deliver the practice: Norwich University College of the Arts, the University of Westminster, and De Montfort University. All partners delivered a range of art and design courses, using a variety of complementary learning techniques.

The project was set up to investigate how changing teaching and assessment practice could be beneficial to different learning styles. The contextual justification for this action research project was to investigate effective practice to retain students within their higher level courses and to support their successful attainment. The project was funded by the Higher Education Academy for a three year period, during which the United Kingdom educational landscape changed rapidly from a widening access perspective to a more business-orientated model of delivery. To make these changes, technology was shown to be essential to the negotiation that evolved for the learning exchange between the student and staff.

\section{Introduction}

Z vidence drawn from Higher Education Statistical CAgency (HESA, 2005) shows that students with a learning difference (dyslexia) tend to take arts or vocational courses. By this definition, they ghettoize themselves by collecting in educational places that provide a teaching experience conducive to their learning. The visual approaches to learning in art and design are known to be valuable for students in any discipline (Steffert, 1999).

This project investigated such learning and assessment to develop and transfer to other areas of higher education, and sought to look at art and design curriculum, especially with an emphasis on studio critique, aural, and visual learning. The purpose was to develop a student-centred approach in both teaching and assessment that could be transferred to 
other subject areas thereby supporting measurable improvement in levels of student achievement and retention for all students with the ability to progress. The project was set within an inclusive learning context.

From the outset of this project, there was a growing realization that technology would emerge as an important element of the negotiated learning and teaching relationship. The evaluation confirmed this to be the case and if utilized could provide a range of learning interactions, as a consistent negotiated mechanism. The result was teaching and assessment practice that included a wide range of students at different learning levels.

The purpose of this paper is to look at the notion of a student experience enhanced by technology, if used in an interactive and negotiated way between the student and the tutor. Underpinning this negotiated learning exchange was the use of technology to understand better both tutor and student learning styles practice.

Each institution worked with three modules during the life of the project. The institutional tutors came to the consensus that a learning strategy could only be developed in dialogue with the student. The underpinning principle for this approach is that a connection has to be made to bridge the gap between the learning and the activity. A depth of student and staff understanding can then happen to enable strategies for student engagement.

The practice bridged this gap and enabled students to develop strategies that allowed them to engage with a range of assessment tools, making the link between learning style and assessment task. Visual and aural strategies were used to develop cognitive thinking. The outcomes were: increased learner confidence in their studies, and the development of student managed support networks.

\section{Methodology}

Ten staff and over 300 students took part in the evaluation process, made up of a mixed-method qualitative and quantitative approach. Questionnaires provided a baseline for student experience on entry to the modules and tracked experience on exit from each module; one-on-one interviews provided additional depth of understanding about staff and student experience; and focus groups provided a rich source of material around the effectiveness of the assessment practice developed. Each student completed learning styles questionnaires at the beginning of each module. However, a key finding was that textbased questionnaires are prescriptive and therefore not entirely accessible to students with a range of learning approaches. Open-ended questionnaires were conducted halfway through each module, and scaled questionnaires on exit from the module.

It was important to ensure that the same format of questionnaire was used for continuity of approach. It was found that the scaled questionnaires elicited a more student focused response whereas the open-ended questionnaires were more tutor directed. Also, in some cases students were to understand their preferred way of learning (if this had not been apparent to them), yet many did not take ownership of that knowledge after completion of the module within the research project.

In the final year of the project, the institutional tutors began to produce talking head diaries, which were then placed on a Vimeo site (http://vimeo. com/user2956163). The InCurriculum website also profiled the methodology and a set of resources drawn from the project. www.incurriculum.org.uk

Educationalists were able to provide feedback on the project progress during a series of seminars. The overriding theme with came through was that effective student centred teaching and learning was essential for student retention. The following points were also listed:

- Learners must be strategic.

- Learning spaces must be used as an open space for implicit and explicit learning.

- Students should be treated as the producer and expert for peer assessment in learning

- Staff must hear the evidence from students and reconnect with the student experience. 
- There should be more of a connection between curriculum design and policy.

- Institutional processes should be put into place for internal subject reviews.

- The package of materials must be available for different validation.

- Students must be given the opportunity for different assessment methods.

- Cases should be proposed to validation committees for different assessment strategies.

\section{The Student Experience Enhanced by Use of Technology}

Evaluation findings showed that good teaching practice, such as setting learning goals and providing innovative formative and summative assessment on learning outcomes, was extremely effective; however, more measurable ways of assessing these outcomes was needed. In addition, for these measures to be put in place, tutors felt they needed more time to prepare materials and alternative methods of assessment due to heavy workloads elsewhere.

A consistent theme that emerged was the excellence of the student-tutor dialogue and the need for this to be maintained for a positive and successful student experience.

\section{Technology}

Substantial feedback from the students showed that they did not see activities in a virtual environment as learning. For many students the personal contact with the tutor was deemed as learning. Students felt disengaged in a virtual environment and yet if managed, in negotiation with the tutor, technology became a highly valued way of interacting (Hepplestone et al., 2011). The negotiation involved tutors using online resources to free up time to do more intensive tutorials with eLearning tasks used to accommodate different learning styles. Different types of visual communication were identified such as, video and iPhones.
The aural feedback emailed as an MP3 file gave students more meaning and context through voice intonation rather than written feedback. However, tutors realized that these methods had to be linked with a record of grades as being essential for consistency between paperwork, video, and sound files. Marking, instruction (use of PowerPoint), and online assessment occurred through Camtasia - by working on the document itself. With Camtasia, the screen-back facility enabled visual feedback comments. Tutors found that students became more engaged and gained a greater understanding about how to improve their work.

\section{Feedback}

The combination of online and face-to-face teaching and learning methods were highly valued. Students wondered: "why use digital media when you can just come and talk." However, the ability to reflect in their own time, to have space for learning, flexible means of accessing feedback, and choice on formative assessment methods was considered extremely helpful when integrated with face-to-face contact. Students stated that the project practice had enabled them create a discourse about their own learning with their peers and tutors, which supported their progression. Evidence of student progression was captured through tutor and student tutorials and progression to further study.

\section{Recommendations}

\section{Practice}

As this was a three year project there were many varied suggestions and recommendations for future practice:

1) Technology should be used to support student learning by making a range of materials available and enabling independent study through flexible use of learning spaces, such as 
televisions, laptops, and iPhones.

2) Tutorial systems should be transferred to the Virtual Learning Environment (VLE), and the learning styles approach reconfirmed on the VLE to assist reflection on learning.

3) MP3 feedback can be used for assessment purposes, particularly within group discussion situations, and to provide a more structured approach for the purposes of formative assessment.

4) Criteria of assessment should be made clear and informed to the students with feedback that is constructive, specific, critical, and easily accessible.

\section{Policy}

5) Evidence of student progression should be captured for institutional policy development on assessment frameworks.

6) Cases of good practice for inclusive student centre assessment should be included to validate committees for the planning of different assessment strategies.

7) Staff toolkits (guidance materials) should be available for validation committees to implement assessment practice.

8) Because many students did not see the VLE as a learning environment or tool, VLE as a learning environment should be investigated.

\section{Conclusion}

Tutors soon realized that different delivery methods could be used for different learning styles. Changes to course material helped student comprehension. Use of technology was linked to each element of teaching so that the learning tasks could be mapped against the outcomes.
There was a greater emphasis on formative assessment with use of peer student feedback through discourse and visual methods. The formative assessment approach gathered evidence about the value of interactive learning that also provided learning space to enable students to reflect in their own time. This approach provided a flexible way for students to gain knowledge of their learning and reconfirm the learning acquired. It was apparent that imaginative use of technology enabled different assessment approaches that could be presented in different formats, such as a wiki or MP3. Tutors did, however, mention that this imaginative use of technology meant additional teaching time was spent on this practice. This presented a challenge to several tutors due to other commitments. It is proposed that this would be an area for additional research.

\section{References}

AchieveAbility. Retrieved from http://www. achieveability.org.uk

Hepplestone, S., et al. (2011). Using technology to encourage student engagement with feedback a literature review. Routledge.

Higher Education Statistics Agency. Retrieved from http://www.hesa.ac.uk

InCurriculum. Retrieved from http://www. incurriculum.org.uk

InCurriculum vimeo. Retrieved from http://vimeo. com/user2956163

Norden, J. (2011). Promoting the intellectual and personal development of students in a way that embraces diversity. Presentation at the Society for Teaching and Learning in Higher Education Conference, University of Saskatchewan.

Steffert, B. (1999). Visual spatial ability and dyslexia. The London Institute. 


\section{Biography}

Katherine Hewlett is an educationalist and also an expert in project development. After 30 years working in Higher Education, Further Education, and Schools she is undertaking Ph.D. at Norwich University College of the Arts. She provides tuition to a range of educational institutions across the UK sector. She is Founder and a Director of AchieveAbility. 